\title{
Fabrication of 3D monolithic graphene foam/ polycaprolactone porous nanocomposites for bioapplications
}

\author{
Neda Bahremandi Tolou ${ }^{1}$, Hamidreza Salimijazi ${ }^{1, *}$, Theodoros Dikonimos ${ }^{2}$, Giuliana Faggio ${ }^{3}$, \\ Giacomo Messina ${ }^{3}$, Alessio Tamburrano ${ }^{4}$, Annalisa Aurora ${ }^{2}$, and Nicola Lisi ${ }^{2, \star}$ (1) \\ ${ }^{1}$ Department of Materials Engineering, Isfahan University of Technology, Isfahan, Iran \\ ${ }^{2}$ ENEA Casaccia, Italian National Agency for New Technologies, Energy and Sustainable Economic Development, Rome, Italy \\ ${ }^{3}$ Department of Information Engineering, Infrastructure and Sustainable Energy (DIIES), Università Mediterranea of Reggio \\ Calabria, Reggio Calabria, Italy \\ ${ }^{4}$ Department of Astronautical, Electrical and Energy Engineering, Sapienza University of Rome, Rome, Italy
}

Received: 31 August 2020

Accepted: 17 November 2020

Published online:

19 December 2020

(C) The Author(s) 2020

\begin{abstract}
Aiming at the production of light, porous, conductive, biosafe composites, in this paper we are presenting a novel fabrication method for monolithic, threedimensional (3D) graphene foam (GF)/porous polymer composites. The synthesis adopts a novel process architecture by using $\mathrm{Ni}$ foam templates in an inductive heating chemical vapor deposition growth process, and by removing $\mathrm{Ni}$ chemically while retaining graphene integrity by the reversible application of cyclododecane (CD); finally, nondestructive coating procedures with polycaprolactone (PCL) solutions have been developed. The composites can be optimized to enhance electrical conduction, flexibility and mechanical properties, while mixing PCL and CD allows to coat the GF with a novel mesoporous polymer coating. By tuning the GF properties, the typical electrical resistance of the $3 \mathrm{D}$ forms can be reduced to a few $10 \mathrm{~s}$ of Ohms, values that are maintained after the PCL coatings. The current study achieved a GF fraction ranging between 1 and $7.3 \mathrm{wt} \%$, with even the lower graphene content composites showing acceptable electrical and mechanical properties. The properties of these conductive 3D-GF/PCL composites are in line with the requirements for applications in the field of nerve tissue engineering.
\end{abstract}

Handling Editor: Chris Cornelius.

Address correspondence to E-mail: hrjazi@cc.iut.ac.ir; nicola.lisi@enea.it 


\section{GRAPHICAL ABSTRACT}

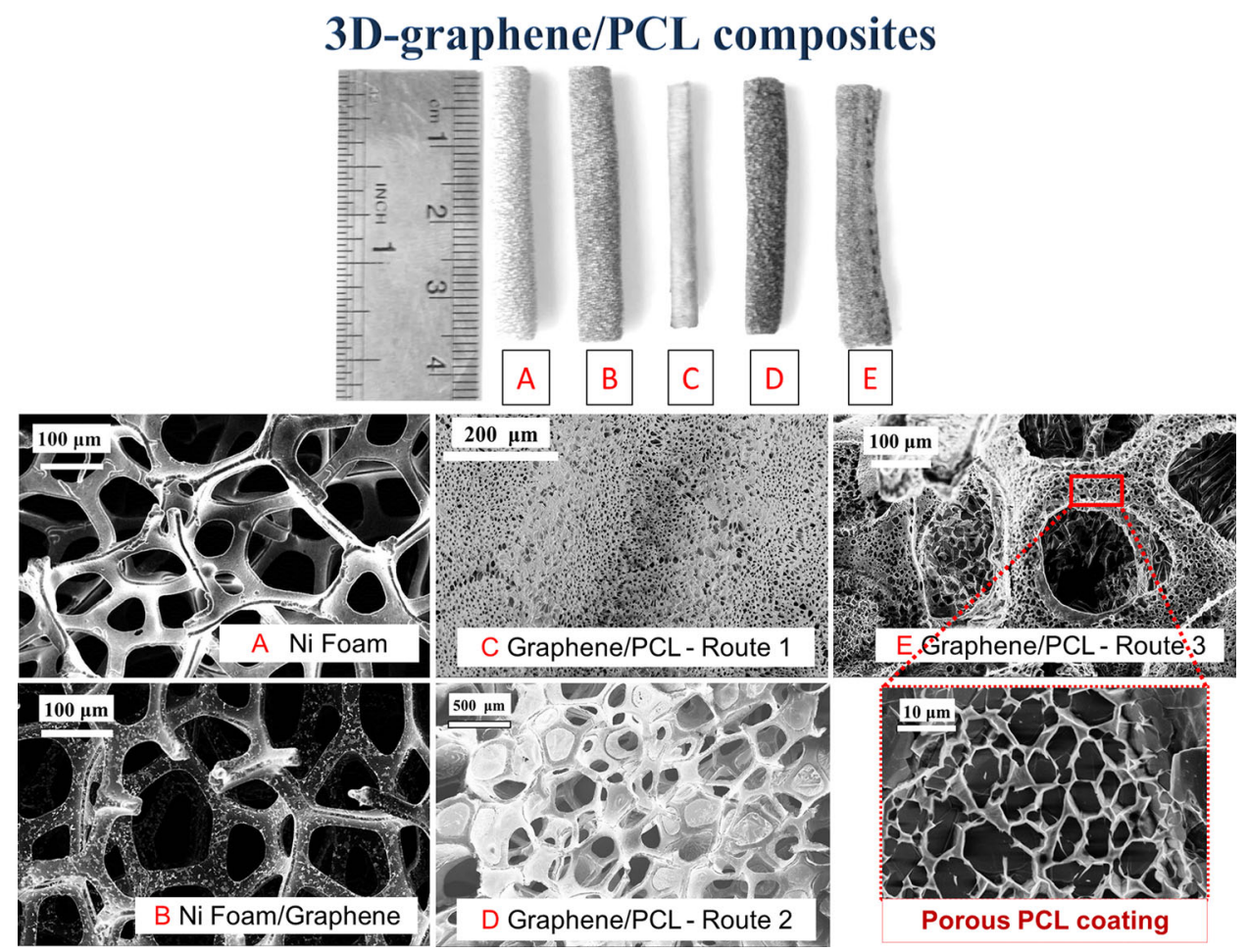

\section{Introduction}

Graphene and graphene-based materials are currently under study for many different applications in diverse fields such as batteries [1], solar cells [2], corrosion prevention [3], chemical sensors [4] and water purification [5]; among these, fields biomedicine and tissue engineering [6] show excellent premises. The addition of nanosized carbonaceous fillers, including graphene family nanomaterials, to polymers may lead to a large enhancement in mechanical, conductive and barrier properties over the pristine polymers [7-9]. Some methods were developed to produce graphene/polymer composite scaffold with complex shapes [10, 11]: Focusing on biomedical applications, a graphene/poly (lactic-coglycolic acid) composite containing $60 \mathrm{wt} \%$ graphene was prepared as a bioink for 3D printing to fabricate a nerve guide conduit [10].
Poly-caprolactone (PCL) is a common polymer frequently used in materials for biomedical applications because of its biodegradability, biocompatibility, ease of fabrication, low processing costs and high solubility in a wide range of organic solvents [12]. The addition of a graphene material to PCL as an electrically conducting and biocompatible filler makes numerous applications possible [13, 14]. However, when graphene materials are randomly distributed in the polymeric matrix in the form of powders or flakes, the electrical conductivity of the composite strongly depends on the electron percolation across different conductive flakes: If the density is low, few conductive paths are available, and the composite exhibits a low overall conductivity [15]. In general, polymer composites based on graphene materials flakes can be prepared also in the form of porous scaffolds by various methods such as solvent casting, gas foaming, phase separation, melt molding technique, emulsification, freeze-drying/lyophilization, electrospinning, microfluidic technique, photo- 
polymerization, micromolding and bioprinting; each technique leads to composite scaffolds with different properties [16].

In contrast, when applying fillers made of interconnected and monolithic networks of graphene (3Dgraphene) where electrons can move freely, the electrical conductivity is higher [11, 17, 18] and almost independent of graphene loading. Due to this attractive feature, the preparation of 3D-graphene/ polymer composites has been investigated and several different preparation methods have been reported $[15,17,19]$.

The chemical vapor deposition (CVD) growth of 3D-graphene on $\mathrm{Ni}$ templates [17] is currently a general strategy for the preparation of the filler structure of continuous matrix composites [20-22]. However, a 3D graphene polymer composite with the same open-pore structure of the Ni template, that is, a 3D-graphene foam (3D-GF), is desirable in many ways: It can be light, strong, flexible and electroconductive while also allowing the passage of liquids and gases [23-25].

During CVD, the precursors decompose on the hot $\mathrm{Ni}$ surface and carbon atoms dissolve into the Ni bulk to form a solid solution [26], and then, upon cooling, the carbon solubility drop forces out carbon atoms to precipitate on the surface and form a thin, nanometer-thick, graphite layer generically referred to as "graphene" [27, 28].

The separation of graphene, or extraction, from the growth catalyst requires the use of etchants (such as $\mathrm{FeCl}_{3}$ ), and the help of a temporary support to avoid damage and to ease the handling of a few atom-thick material is required. Polymethyl methacrylate (PMMA) is frequently applied since it is easy to handle and readily available [29]: However, its removal requires the use of a solvent bath which poses a challenge to the sample integrity. It has also been documented that the PMMA procedure is rather complex if one has to remove all its residues [30]. In order to avoid the solvent bath, problematic for the sample integrity, we rather applied cyclododecane (CD) [31] as a temporary protective layer. This waxy solid easily coats graphene materials to assist the wet etching of nickel, and it is removed by mild thermal processes only.

As stated, the 3D-GFs grown by CVD on nickel templates show higher electrical conductivity than those made by chemical process such as freeze-drying, hydrothermal gelation, vacuum filtration and sugar blowing [32]. However, for a device to be conductive, the GF must be continuous over the full size and one of the main challenges for making devices on the scale of several centimeters is the handling capability and survival of GF when deployed. In conclusion, the practical application of $3 \mathrm{D}$ graphene must be in the framework of composites [33], where a polymer provides some mechanical strength to the GF.

In the current paper, the fabrication of three-dimensional, monolithic and interconnected GF tubes and slabs coated with PCL and a length of several $\mathrm{cm}$ is presented for the first time. First, the 3D-GF structure is grown by CVD on $\mathrm{Ni}$ templates. Then, $\mathrm{Ni}$ is removed by applying $\mathrm{CD}$ as a temporary protective layer to protect the tenuous graphene frame during the wet etching of $\mathrm{Ni}$ in repeated $\mathrm{FeCl}_{3}, \mathrm{HCl}$ and distilled water baths. CD is then easily removed by mild thermal processes without the use of solvents, leaving no residues and requiring no further processing [31]. Finally, PCL is applied to the free-standing 3D-GF.

\section{Experimental methods}

\section{Synthesis of 3D-graphene by ICVD}

The 3D scaffold templates (Figure S.1.a) are made of nickel foams, with 130 PPI pore density and $1.5 \mathrm{~mm}$ in thickness (Henzen Group, China, > 99.8, $320 \mathrm{~g} \mathrm{~m}^{-2}$ in areal density); dichloromethane $\left(\mathrm{CH}_{2}\right.$ $\mathrm{Cl}_{2}$, Merck), ethyl acetate $\left(\mathrm{C}_{4} \mathrm{H}_{8} \mathrm{O}_{2}\right.$, Applichem), $\mathrm{FeCl}_{3}$ (Sigma) and $\mathrm{HCl}$ (Merck) were used, all chemicals being technical grade. For making 3D-GF tubes, nickel foams were cut to size and rolled around a 3-mm polytetrafluoroethylene (PTFE) tube template and their edges crimped (Figure S.1.b). Graphene was grown in an inductive heating CVD (ICVD) system, based on the remote heating of a graphite susceptor sample holder placed inside the quartz reactor chamber. To ensure accurate temperature regulation, the power supply implements a closed-loop control with a type-K thermocouple buried inside the susceptor. Digitally controlled mass flow meters (MKS), a progressive manual leak valve and a rotary vane pump provide control on precursor flow and pressure. ICVD was adopted due to its advantageous features like fast heating and cooling, along with high throughput and reduced contamination. 
Figure S.2.a shows the schematic arrangement of the ICVD apparatus. Figure S.2.b elaborates the T-t diagram of the process that comprises several growth steps. The prepared growth samples are placed in the susceptor crucible and inside the quartz vessel, and after evacuation, they are set under flowing Ar (20 standard cubic centimeter per minute, SCCM) and $\mathrm{H}_{2}$ (20 SCCM) and heated at $280{ }^{\circ} \mathrm{C}$ for degassing under low pressure for $5 \mathrm{~min}$. In the next stage, the temperature is increased to the desired level for graphene growth, followed by an annealing process under constant temperatures to eliminate possible contaminations and reduce the surface for $10 \mathrm{~min}$. The mixture was replaced by $\mathrm{CH}_{4}$ and $\mathrm{H}_{2}$ with the gas flow adjusted, respectively, at 14 and 7 SCCM for the growth that was carried out at the three growth temperatures selected for this work: $880{ }^{\circ} \mathrm{C}, 980{ }^{\circ} \mathrm{C}$ and $1080{ }^{\circ} \mathrm{C}$. The last stage rapid cooling was carried out while filling the chamber under $\mathrm{Ar}$ and $\mathrm{H}_{2}$ with 750 SCCM and 50 SCCM, respectively.

The as-grown samples are taken to further processing to extract graphene. First, CD is applied to the surface by dip coating, and after that, they are immersed in $\mathrm{FeCl}_{3}$ water solution with the concentration of $100 \mathrm{~g} \mathrm{l}^{-1}$ for 12 to $48 \mathrm{~h}$ at $4{ }^{\circ} \mathrm{C}$ to dissolve the $\mathrm{Ni}$ and then in $10 \% \mathrm{v} / \mathrm{v} \mathrm{HCl}$ solution for at least $1 \mathrm{~h}$ to remove possible iron $(\mathrm{Fe})$ residues. A small commercial $\mathrm{Nd}$ magnet can be employed to test the complete etching, when floating samples stop moving in its field. The CD is finally removed by sublimation under mild heating $\left(60^{\circ} \mathrm{C}\right)$ leaving the freestanding 3D graphene samples. The 3D-GF tube sample integrity is promoted by the use of a semirigid polytetrafluoroethylene (PTFE) tubing inner support.

\section{D-GF and PCL composites fabrication}

In the current research, the fabrication of 3D-GF/PCL composites is processed through several processing routes as shown in Fig. 1. Investigations were performed using PCL CAPA 6500 (84,500 MW), supplied from Perstorp Co., UK .

To evaluate the behavior and characteristics of PCL scaffold samples, investigations were performed also without 3D-GF. For the latter case, a clean tubeshaped Ni foam is directly dip coated with PCL in dichloromethane (DCM). After drying the solvent, the sample is further dip coated with $\mathrm{CD}$ in ethyl acetate (ETAC) to protect PCL during Ni etching.
Finally, the sample was dried at up to $60^{\circ} \mathrm{C}$ for 16-20 $\mathrm{h}$ to get rid of CD and solvents.

Samples are evaluated for their electrical and mechanical characteristics in the following sections. $\mathrm{Ni}$ foam/3D graphene deposited at various growth temperatures was applied using four processing routes to evaluate their impacts on the electrical and mechanical characteristics of the graphene/PCL composite.

\section{Route-1 (Drop-dip): successive drop and dip coating with PCL, after extraction}

In this method, 3D-GF was extracted from Ni foam/ 3D-graphene sample by applying CD on it, initially. Then, $\mathrm{Ni}$ is removed by $\mathrm{FeCl} 3$ and $\mathrm{HCl}$ solutions as already explained. After Ni removal, the free-standing 3D-GF was coated with PCL in DCM in several successive steps, first by drop and then by dip technique.

Route-2 (PCL-CD): successive PCL and CD dip coating, before extraction

In this process, $\mathrm{Ni}$ foam/3D-graphene sample was first dip coated with PCL in DCM and, after drying, further protected by a CD layer deposited via dip coating with $\mathrm{CD}$ in ETAC prior to $\mathrm{Ni}$ removal (PCL does not dissolve in ETAC). $\mathrm{Ni}$ is then removed by $\mathrm{FeCl} 3$ and $\mathrm{HCl}$.

Route-3 (Mix): PCL and CD mixed solution dip coating, before extraction

In this procedure, before $\mathrm{Ni}$ removal step, the $\mathrm{Ni}$ foam/3D-graphene sample was dip coated in a mixed PCL and CD, DCM solution. $\mathrm{Ni}$ is then removed by $\mathrm{FeCl} 3$ and $\mathrm{HCl}$.

The identification codes for all samples are listed in Table 1, and a photographic image of different samples is shown in Fig. 2.

\section{Characterizations of 3D graphene and 3D graphene/polymer composites}

Several characterization techniques were applied systematically to evaluate the process impacts on mechanical and electrical properties. Raman scattering measurements were carried out at room temperature by a HORIBA Scientific LabRAM HR Evolution 
Figure 1 Schematic of fabrication processes of 3DGF/PCL composites.

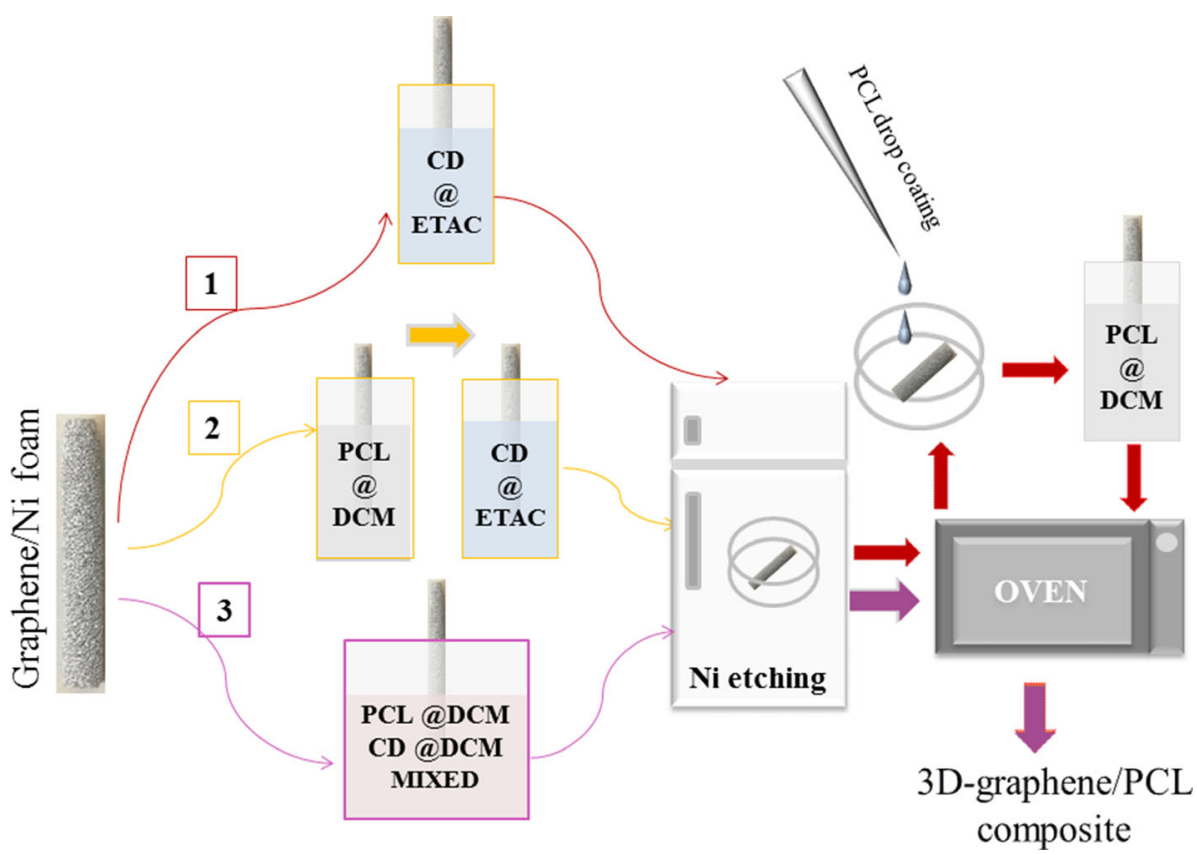

Table $13 \mathrm{D}-\mathrm{GF} / \mathrm{PCL}$ composites code and processing method

\begin{tabular}{lll}
\hline 3D-GF/PCL composite code & Processing route & Graphene growth temperature, ${ }^{\circ} \mathrm{C}$ \\
\hline Drop and dip-980 & 1- Successive drop and dip coating with PCL after extraction & 980 \\
Drop and dip-1080 & 1- Successive drop and dip coating with PCL after extraction & 1080 \\
PCL-CD-880 & 2- Successive PCL and CD, dip coating before extraction & 880 \\
PCL-CD-1080 & 2- Successive PCL and CD, dip coating before extraction & 1080 \\
Mix-1080 & 3- PCL and CD mixed solution, dip coating, before extraction & 1080 \\
PCL scaffold & 2- Successive PCL and CD, dip coating before extraction & No growth \\
\hline
\end{tabular}

Figure 2 A photographic image of 3D graphene structures prepared by different methods.

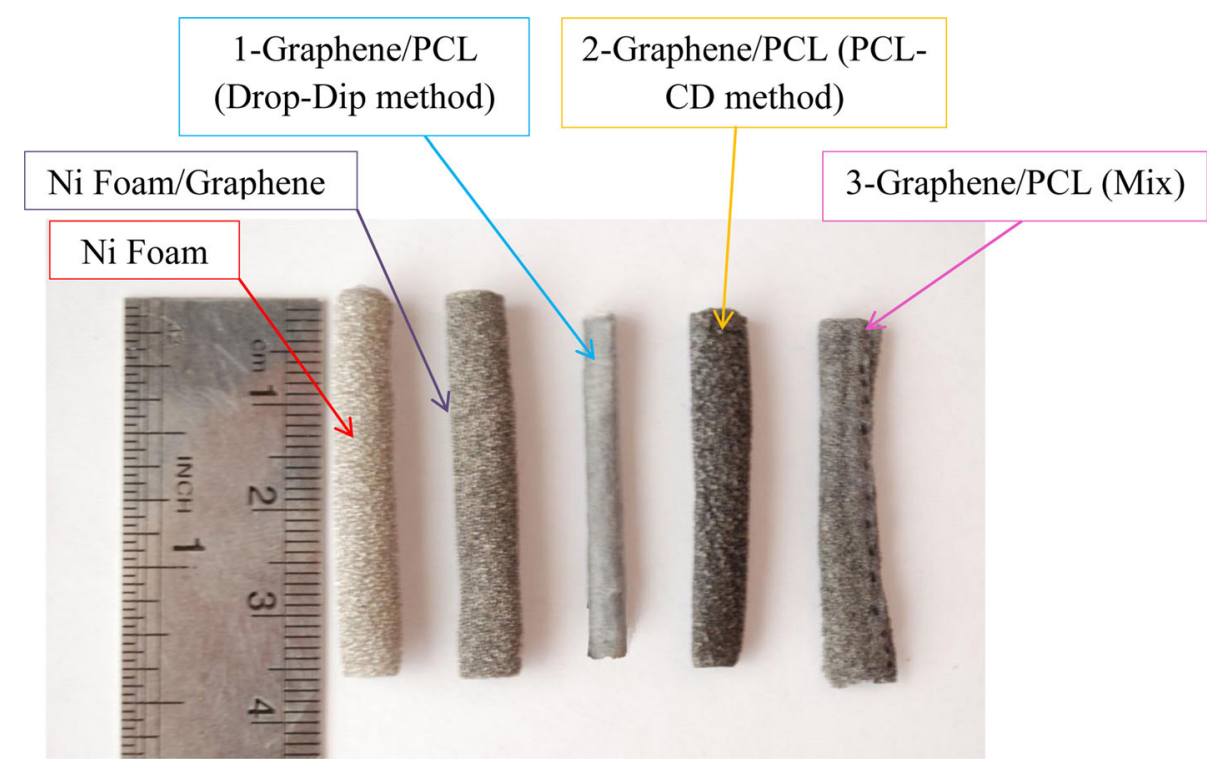


Raman spectrometer equipped with an integrated Olympus BX41 microscope. Laser excitation wavelength of $532 \mathrm{~nm},(2.33 \mathrm{eV})$ was focused on the sample surface using a $100 \times$ objective with a spot size of approximately $1 \mu \mathrm{m}$. Low laser power (below $1 \mathrm{~mW}$ ) was used which minimized sample heating and avoid sample damage. The morphology and structure of samples were studied by scanning electron microscope (Zeiss, Gemini-LEO 1530).

Uniaxial tensile tests were conducted on the hollow tube-shaped samples by using an electromechanical universal testing machine, model Instron 3366 (Figure S.3.a).

The X-ray photoelectron spectroscopy (XPS) analysis was performed to evaluate the surface chemical composition of samples and to assess the complete removal of Ni. All XPS spectra were taken in a Vacuum Generators Escalab MK II, equipped with oil-free pumps. Spectra were acquired in a vacuum of $3.10^{-9}$ torr with $\mathrm{MgK} \alpha$ line source at $1253.6 \mathrm{eV}$.

The weight percent of carbon on $\mathrm{Ni}$ foam was calculated by measuring the weight of samples before and after graphene growth (Eq. 1):

Carbon weight percent $=\frac{W_{\mathrm{Gr} / \mathrm{Ni}}-W_{\mathrm{Ni}}}{W_{\mathrm{Ni}}} \times 100$

where $W_{\mathrm{Ni}}$ and $W_{\mathrm{Gr} / \mathrm{Ni}}$ are Ni foam weight and graphene/Ni foam weight, respectively. Standard deviation was calculated based on three samples measurements.

The thermal analysis has been carried out in SDT Q600 (TA Instruments) with a linear heating rate of $10{ }^{\circ} \mathrm{C} / \mathrm{min}^{-1}$ from room temperature to $500{ }^{\circ} \mathrm{C}$ in $\mathrm{N}_{2}$ atmosphere. The $\mathrm{N}_{2}$ purge flux was $100 \mathrm{~mL} / \mathrm{min}$. The measurements have been carried out in an $\mathrm{Al}_{2} \mathrm{O}_{3}$ crucible, and the initial weights have been maintained about 4-4.5 $\mathrm{mg}$ for all samples.

\section{Results and discussion}

\section{D-Graphene characterization}

Characterization on the samples by Raman spectroscopy confirms that the 3D-GF is made of thin graphite, i.e., the different graphene layers appear to have a stacking order and are not independently oriented to each other. The Raman spectra of graphitic carbon are dominated by two main peaks: G-peak at $\sim 1582 \mathrm{~cm}^{-1}$ due to the in-plane bond stretching of all pairs of $\mathrm{sp}^{2}$-carbon atoms in both rings and chains and 2D-peak at $\sim 2670 \mathrm{~cm}^{-1}$ that originates from a double resonance Raman process [34]. The presence of disorder and defects in graphene materials activates the D-peak at $\sim 1350 \mathrm{~cm}^{-1}$ due to a breathing mode of six-atom rings, and the $\mathrm{D}^{\prime}$-peak at $\sim 1620 \mathrm{~cm}^{-1}$ [35].

Commonly, the D-to-G intensity ratio $\left(I_{\mathrm{D}} / I_{\mathrm{G}}\right)$ is used as Raman indicator of crystalline quality $[36,37]$, where small values are indicative of a low defect density. The $2 \mathrm{D}$-to-G intensity ratio $\left(I_{2 \mathrm{D}} / I_{\mathrm{G}}\right)$ is regarded as a qualitative parameter to evidence the presence of very few sheets of graphene: Single layer (1L) or bilayer (2L) is characterized by $I_{2 \mathrm{D}} / I_{\mathrm{G}}>1$, while in multilayer graphene $I_{2 \mathrm{D}} / I_{\mathrm{G}}<1$ [38]. The frequency, the shape and the full width at half maximum (FWHM) of the 2D-peak provide further information on the number and on the stacking order of graphene layers [39]. A single Lorentzian component $\left(\mathrm{FWHM} \sim 24 \mathrm{~cm}^{-1}\right.$ ) well reproduces the 2Dpeak of single-layer graphene, whereas the Raman spectrum of multilayer graphene (number of layers $>5$ ) is hardly distinguishable from that of the bulk material. In turbostratic multilayer graphene, where there is no stacking order between adjacent graphene layers, the 2D-peak is again described by one Lorentzian component but with a larger line

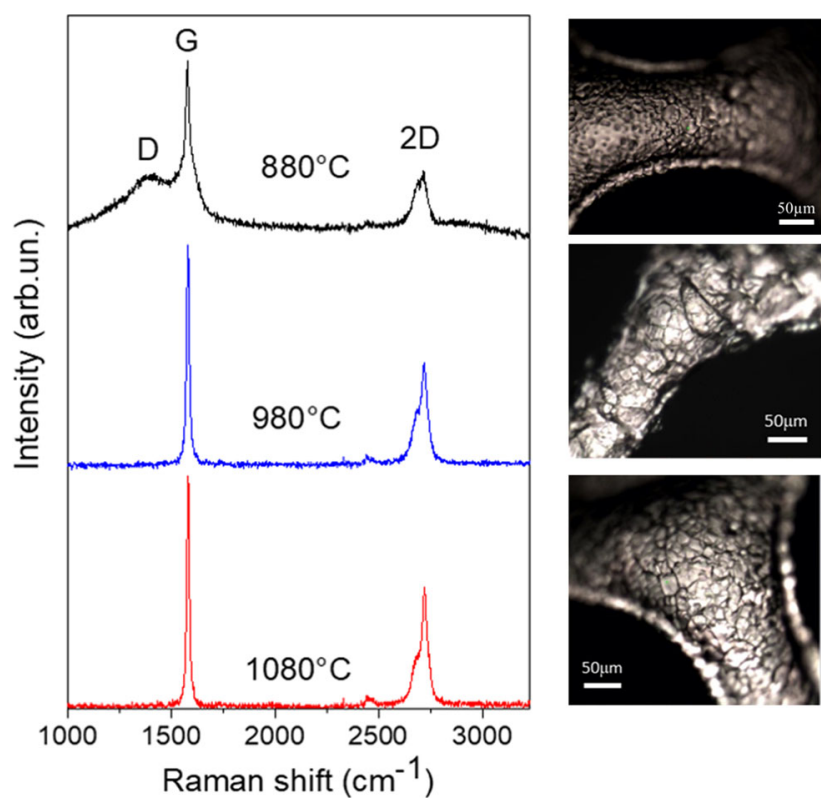

Figure 3 Raman spectra of $3 \mathrm{D}$ graphene samples grown on nickel foam at $880{ }^{\circ} \mathrm{C}$ (black), $980{ }^{\circ} \mathrm{C}$ (blue) and $1080{ }^{\circ} \mathrm{C}$ (red). The spectra are normalized to the G-peak. The corresponding optical micrographs are on the right side of the figure. 
width (FWHM $\sim 45-60 \mathrm{~cm}^{-1}$ ) and with a frequency upshifted with respect to the $1 \mathrm{~L}$ graphene $[39,40]$.

The Raman spectra of the samples grown in the 880-1080 ${ }^{\circ} \mathrm{C}$ temperature range and their corresponding optical images are reported in Fig. 3. At $980{ }^{\circ} \mathrm{C}$ and $1080{ }^{\circ} \mathrm{C}$, the $3 \mathrm{D}$ graphene samples show similar Raman spectra. The asymmetrical shape of the 2D-peak closely resembles that of highly oriented pyrolytic graphite (HOPG) [39] and, together with its relative intensity with respect to the G-peak, points to the structure of thin graphite [20]. The absence of D peak and the sharp G-peak $\left(\sim 14 \mathrm{~cm}^{-1}\right)$ witnesses the high crystalline quality of these 3D-GF samples. At $880{ }^{\circ} \mathrm{C}$, the peaks become very broad and a large $\mathrm{D}$ peak appears indicating a more disordered material.

Figure 4 presents scanning electron microscopy (SEM) micrographs of the 3D graphene networks as grown on the $\mathrm{Ni}$ foam at the different temperatures. The Ni foam is entirely covered, but on the microscale, the coating is not entirely homogenous, as revealed by the presence of patches of different intensities in the SEM micrographs. They show that the Ni surface consists of a patchwork of crystalline grains and of grain boundaries that favor the formation of inhomogeneous graphene deposits [26]. Furthermore, some wrinkles and ripples can be observed on the surface attributed to the different thermal contraction of $\mathrm{Ni}$ and graphene $[17,21]$ upon cooling.

With the increase in growth temperature, the $\mathrm{Ni}$ surface becomes "darker" in the micrographs, indicating electron absorption by thicker carbon, while for graphene grown at $880{ }^{\circ} \mathrm{C}$, the graphene layer is thinner and less evident by SEM (Fig. 4a). The surface appears homogeneous, and only some narrow wrinkles (white arrows in Fig. 4b) hint to the presence of graphene. From a practical point of view, this observation corresponds to the fact that at such temperature, after removing $\mathrm{Ni}$ from graphene, it was hardly possible to achieve free-standing GF.
Figure 4 SEM micrographs of graphene grown on nickel foam at (a), b $880{ }^{\circ} \mathrm{C}$; $\mathbf{c}$, d $980{ }^{\circ} \mathrm{C}$; e, f $1080{ }^{\circ} \mathrm{C}$.
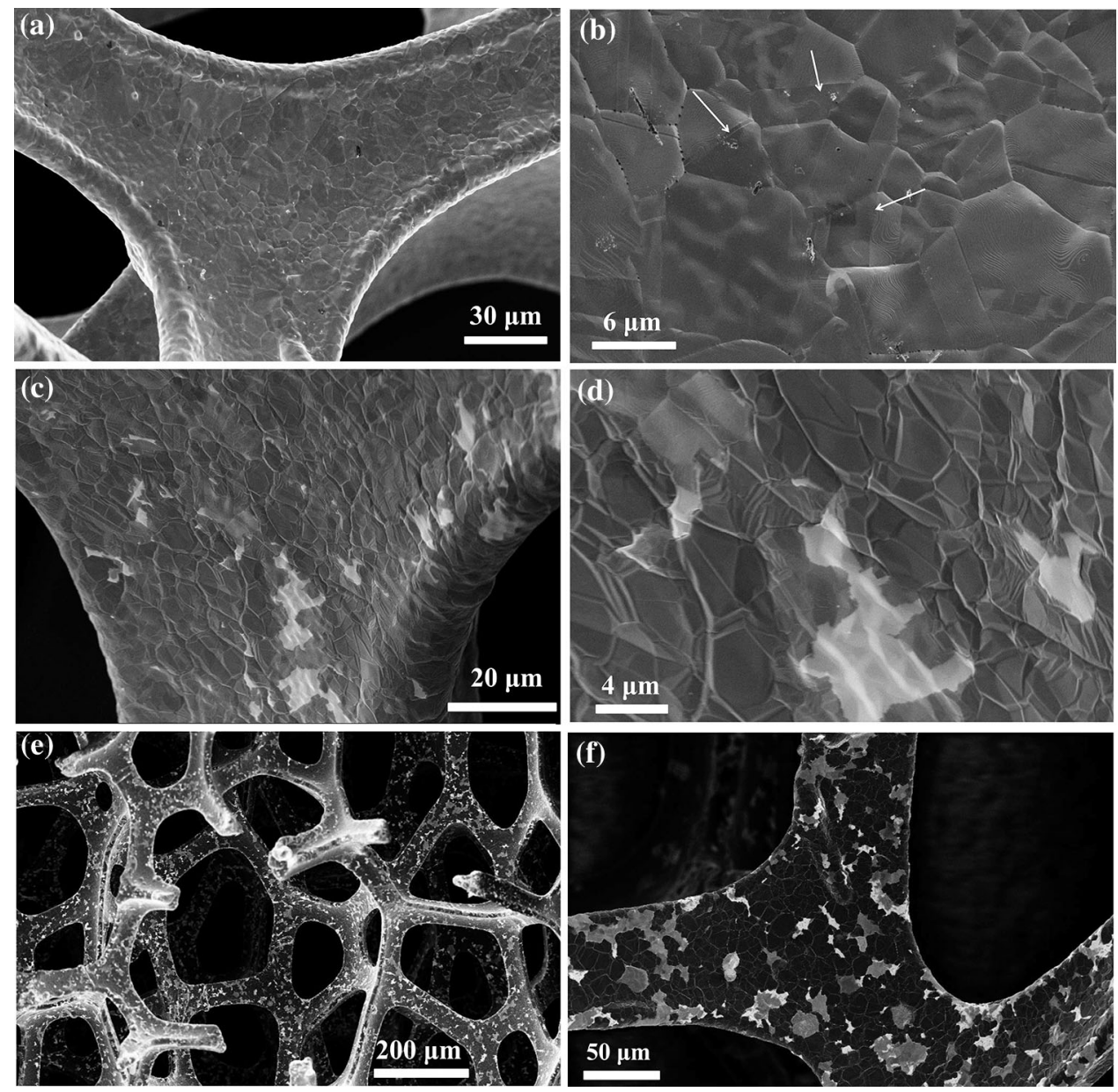
Table 2 Weight percent of carbon by experimental and calculation from Ni-C diagram phase

\begin{tabular}{lll}
\hline Graphene growth temperature $\left({ }^{\circ} \mathrm{C}\right)$ & Weight percent of carbon, experimental & Weight percent of carbon, phase diagram \\
\hline 880 & $0.17 \pm 0.05$ & 0.15 \\
980 & $0.42 \pm 0.12$ & 0.24 \\
1080 & $0.57 \pm 0.05$ & 0.33 \\
\hline
\end{tabular}

The weight changes of samples after CVD growth were also measured. The results are displayed in Table 2 (and plotted in Figure S.4). The mass of dissolved carbon in $\mathrm{Ni}$ increases when the deposition temperature is raised. It can be found from the $\mathrm{Ni}-\mathrm{C}$ phase diagram that the weight percent of carbon in $880{ }^{\circ} \mathrm{C}, 980{ }^{\circ} \mathrm{C}$ and $1080{ }^{\circ} \mathrm{C}$ is $0.15,0.24$ and $0.33 \mathrm{wt} \%$, respectively [41]. The measured weight increase in this study at 980 and $1080{ }^{\circ} \mathrm{C}$ is higher than that of dissolved carbon in $\mathrm{Ni}$, as calculated from the normal solubility of the C-Ni phase diagram (Table 3). This implies that the growth on $\mathrm{Ni}$ is not simply due to $\mathrm{C}$ dissolution during heating and precipitation during cooling [26, 27], but that it occurs during the heating phase due to instabilities and possibly by a surface growth mechanism [21]. In practical terms, at higher temperature a "bulkier" GF is grown and implementing free-standing 3D-GF becomes easier.

The GF was further characterized by XPS, before and after the removal of $\mathrm{Ni}$. After the growth, the spectra only showed $\mathrm{C}$ and $\mathrm{Ni}$, with some $\mathrm{O}(<4 \%)$, both adsorbed and $\mathrm{Ni}$ bonded (spectra not reported here). After the separation, in the free-standing samples only $\mathrm{C}$ and $\mathrm{O}(\mathrm{O} \sim 15 \%)$ were detected without any amount of $\mathrm{Ni}$ and $\mathrm{Fe}$ as catalyst and etchant residues. Figure S.5 displays the $\mathrm{C} 1 \mathrm{~s}$ peak for graphene grown at $1080{ }^{\circ} \mathrm{C}$ which is typically graphitic $\left(\mathrm{sp}^{2}\right)$ with some oxidized features. Most of the $\mathrm{O}$ component in free-standing GF then originates during the strongly oxidizing $\mathrm{Ni}$ etching procedure.

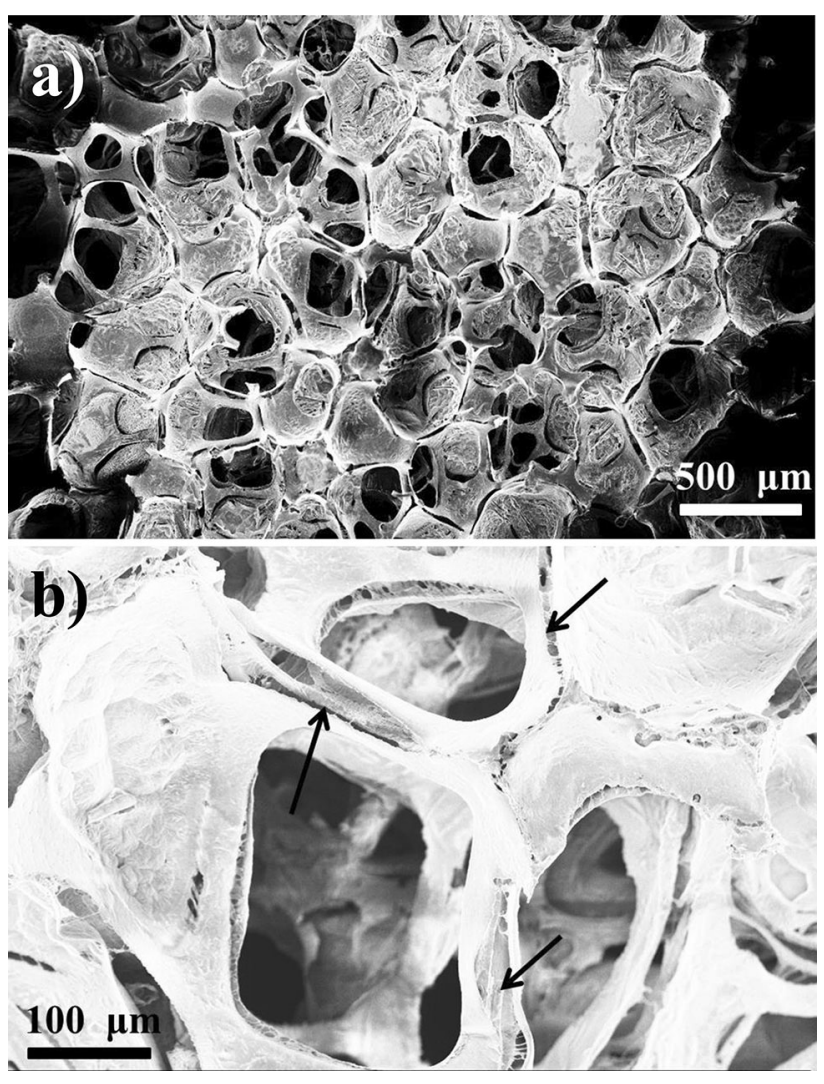

Figure 5 a SEM micrographs of PCL scaffold by Route-2 and $\mathbf{b}$ higher magnification.

Table 3 Mechanical properties of 3D graphene/polymer composites

\begin{tabular}{llll}
\hline 3D-GF/PCL composite code & Young's modulus (MPa) & Ultimate tensile stress (UTS) (MPa) & Strain at failure (\%) \\
\hline Free-standing GF [33] & 0.34 & 0.0048 & 5 \\
PCL scaffold & 0.62 & 0.06 & $11 \pm 1.4$ \\
Drop and dip-980* & 2.92 & 0.41 & 18 \\
Drop and dip-1080* & 4.50 & 1.80 & 20 \\
PCL-CD-1080* & 0.01 & 0.45 & 11 \\
\hline
\end{tabular}

*For these samples, there was no repetition. The statistical approach is not adopted in the current study which is extended to the future study 

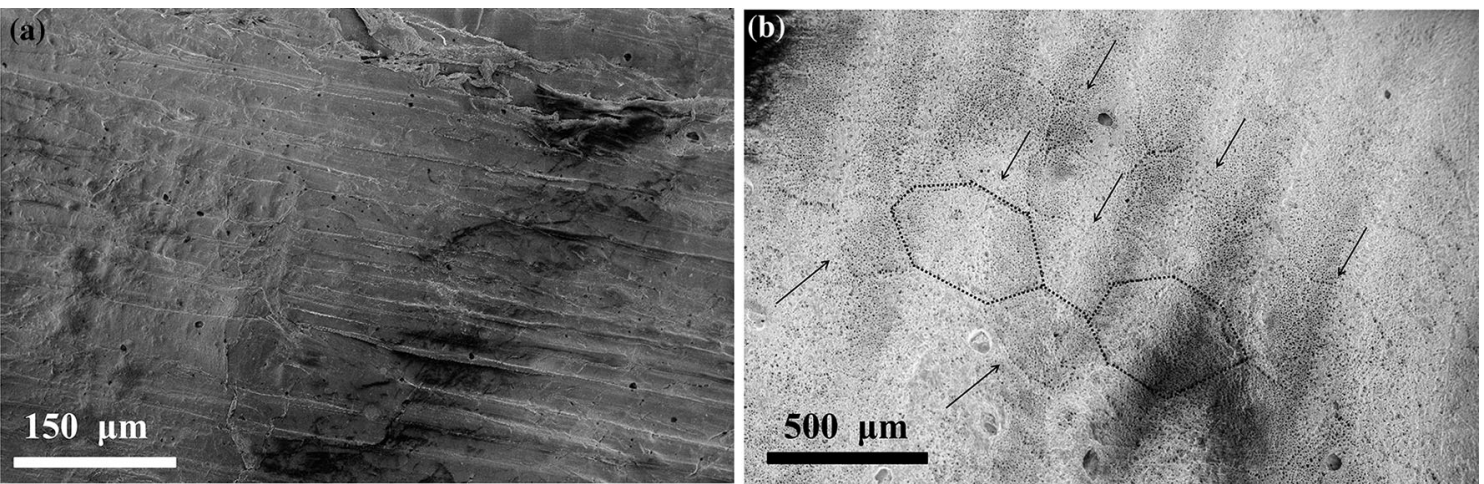

Figure 6 a SEM micrographs of inner surface of 3D-GF composites by Route- 1 with GF grown at $980{ }^{\circ} \mathrm{C}$, and $\mathbf{b}$ outer surface.

\section{Morphology of the 3D-GF composites}

Figure 5 shows the SEM micrographs of PCL scaffold prepared by Route- 2 . When Ni is taken off by etching, some voids are created as highlighted by the arrows in Fig. 5b. Although PCL mostly preserves the $\mathrm{Ni}$ foam structure, some of the foam pores were also filled by the polymer

Figure $6 \mathrm{a}, \mathrm{b}$ indicates, respectively, the inner and outer surface of a foam tube sample prepared by Route- 1 with the graphene grown at $980{ }^{\circ} \mathrm{C}$. Here the coating process of the bare and free-standing GF with polymer solution leads to the visible collapse of the structure porosity which finally is lower in the inner than in the outer tube surface. Besides, in Fig. $6 \mathrm{~b}$, boundary-like features are visible that are the remnants of the collapsed wires of the foam.

Another composite made by Route- 1 with $1080{ }^{\circ} \mathrm{C}$ GF is presented in Fig. 7. In this case, a mechanically stronger graphene framework limited the tube collapse and some open pores are maintained both on the inner and outer surface of the tubes. The ability to tune the composite structure is encouraging for

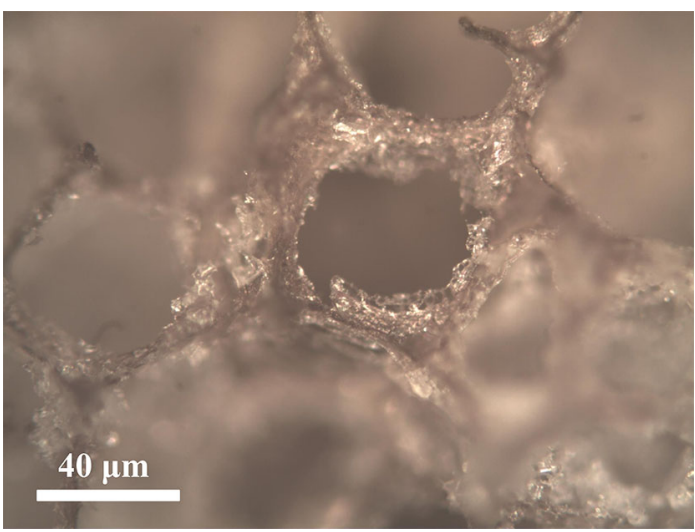

Figure 8 Optical micrographs of 3D-GF composites by Route-2, with $880{ }^{\circ} \mathrm{C}$ grown GFs.

biomedical applications since porosity should be tuned to exchange oxygen, waste materials and cells. It is reported that closed pores do not promote smooth cell migration through the scaffold structure [14].

Optical micrographs of 3D-GF composites by Route- 1 with $880{ }^{\circ} \mathrm{C}$ GFs are shown in Fig. 8. SEM micrographs of 3D-GF composites by Route- 2 with
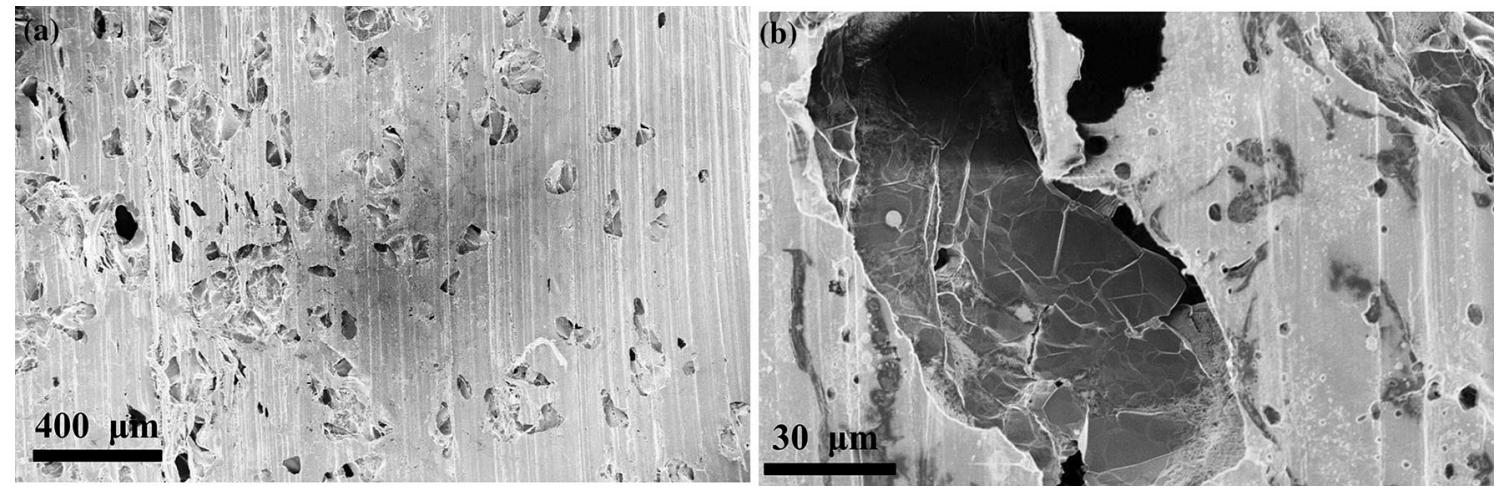

Figure 7 a SEM micrographs of inner surface of 3D-GF composites by Route-1 with GF grown at $1080{ }^{\circ} \mathrm{C}$, and $\mathbf{b}$ higher magnification. 

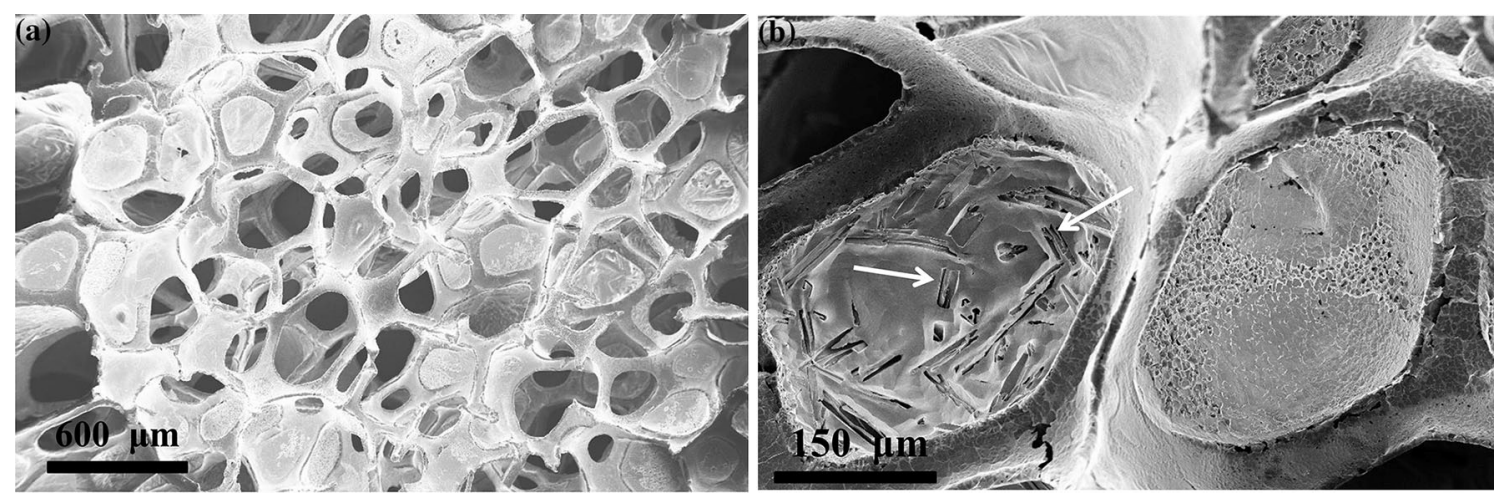

Figure 9 a SEM micrograph of 3D-GF composites by Route-2, with $1080{ }^{\circ} \mathrm{C}$ grown GFs, and b higher magnification.

$1080{ }^{\circ} \mathrm{C} \mathrm{GF}$ are shown in Fig. 9. At $880{ }^{\circ} \mathrm{C}$ (Fig. 8), the graphene struts are thinner, indicating the collapse of the hollows left by the individual Ni strut wires. The overall 3D structure of the $1080{ }^{\circ} \mathrm{C}$ graphene foam is shown in Fig. 9. Some elongated needle-shaped structures are visible on the PCL surface (white arrows in Fig. 9b) related to the footprints of $C D$ crystals after sublimation, suggesting the possibility of structuring the polymer by the use of sacrificial CD inclusions.

Figure 10 displays SEM micrographs of samples prepared with the mixed CD/PCL solutions (Route$3)$, where different relative concentrations were applied as detailed in the caption. Interestingly, in all cases the polymer coating on each strut was itself porous with the presence of polygonal hollow cells. When the solvent (DCM) evaporates, it leaves behind a PCL foam mesh network with small CD volumes (i.e., nucleated CD crystals) analogous to the needleshaped footprint structure shown in Fig. 10d, which in their turn were hollowed out by the sublimation of CD. Such novel mesoporous polymeric structure, which was discovered in the course of this study, is porous on several different dimensional scales: (i) Large pores, about several hundred micrometers, derive from the Ni template; (ii) small pores are due to sublimation of $\mathrm{CD}$ crystals and have a typical micrometer size. The geometric properties of this structure can be changed by varying the relative PCL/CD concentrations from 50\% PCL-50\%CD (Fig. 10a, b) to $80 \%$ PCL-20\%CD (Fig. 10c, d). The 3Dgraphene/PCL composite with $80 \%$ PCL-20\%CD composition is clearly less "microporous" and
Figure 10 SEM micrographs of mixed samples (method 3). a, b $50 \%$ PCL- $50 \% \mathrm{CD}$ and c, d $80 \%$ PCL- $20 \%$ CD.
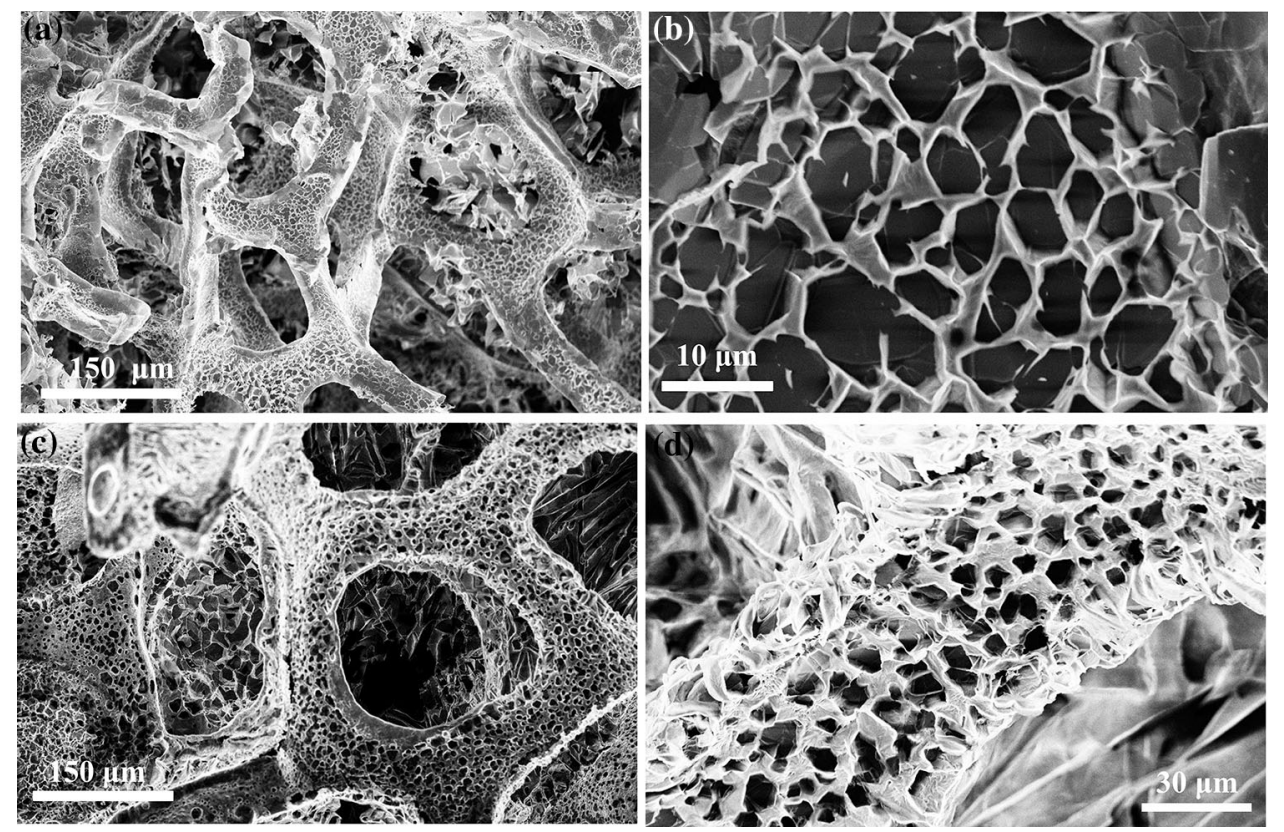
qualitatively had better mechanical properties which made it somehow easier to handle.

\section{Mechanical properties of the 3D-GF composites}

The test results of the samples prepared in this work have been evaluated by comparison with data for free-standing GF and for some animal nerves from other published works, as presented in Table 3 . Samples made by applying mixed PCL/CD solutions (Route-3) did not have sufficient strength, and they were all broken during handling or fixing to the jaws. Samples prepared by drop and dip technique (Route1) exhibited superior mechanical characteristics and flexibility. The samples prepared by PCL-CD (Route2) showed also good mechanical properties, but the flexibility and handing capability were inferior due to the rigidity of the intact (i.e., not collapsed) 3D-GF geometry. It can be concluded that the collapse of the porous structure observed when applying Route-1 apparently improves the overall mechanical properties and the flexibility of the scaffolds.

Nieto et al. measured the mechanical properties of the free-standing GF. They reported its elastic modulus and ultimate strength in tension 339 and $4.8 \mathrm{kPa}$, respectively [33]. Table 3 shows that the 3D-GF/PCL composite developed in this work has the UTS and Young's modulus much higher than PCL sample without graphene (bases on three samples, UTS = $0.06 \mathrm{MPa}$ and Young's modulus $=0.62 \mathrm{MPa}$ ) and also free-standing GF (UTS $=0.0048 \mathrm{MPa}$ and Young's modulus $=0.34 \mathrm{MPa}$ [33]).

By in situ SEM observations, it was demonstrated that the strength in tension of GF can be attributed to the alignment of graphene struts, or "branches", which entwines the high in-plane mechanical properties of graphene [33]. However, since the struts of the 3D graphene structure are not aligned in our foams (they are in fact about $110^{\circ}$ from each on average in the case of tetrahedral strut vertices) [33], alignment requires bending of a rather large angle which fatally collapses the rigid monolithic thin graphite structures, breaking the struts one by one (Figure S.3.b). We suggest that this is why 3D-GF fabricated by Route-1, where the GF collapses during polymer coating into a thin cylinder, effectively aligning the struts, exhibited better mechanical behavior. Therefore, making a Ni foam structure prealigned along tension lines could be a general strategy to improve the mechanical performance of the 3D graphene composites.

\section{Graphene loading and foam density}

To determine the graphene loading in the 3D-GF composites, two methods were applied: (a) measuring the sample weight at different processing stages during fabrication (i.e., before and after growth); (b) thermogravimetric analysis (TGA) of the final samples.

Figure S. 4 shows the relative mass increase in the Ni foam samples after growth. Figure S.6 illustrates TGA, together with derivative thermogravimetry (DTG) spectra for PCL-CD-980 (Route-2) sample.

All samples analyzed by TGA showed that the graphene loading of the 3D-GF/PCL composites is between 2.5 and $7.3 \mathrm{wt} \%$. The carbon mass derived from the weighting method also leads to a graphene content ranging from 1 to $7 \%$ depending on the method for making the composite and on the graphene growth temperature. In conclusion, the graphene loading derived by (a) and that directly measured by (b) are good agreement.

By measuring the sample dimensions and mass, the average foam density can be estimated for the 130 PPI foams employed in the current study. Depending on the processing, density ranged from $0.2 \mathrm{~g} / \mathrm{cm}^{3}$ for the Route- $1,-0.1 \mathrm{~g} / \mathrm{cm}^{3}$ of Route- $2,-0.08$ for Route- 3 .

\section{Electrical properties}

The presence of a monolithic 3D-GF filler provides a parallel (i.e., redundant) network of continuous conductive paths. The electrical resistivity and electrical conductivity were calculated by measuring the electrical resistance and taking into account the dimensions of samples, as listed in Table 4 . Instead in all the composites samples prepared in this study, the electrical resistance of the tube or slab samples ranged from 17 to $550 \Omega$ depending on the fabrication process. Qian et al. prepared a conductive nerve guide conduit by layer-by-layer coating method. They used two solutions for different layers coatings: PCL and single-layer graphene (SG) or multi-layer graphene (MG) solution and polydopamine (PDA) and arginylglycylaspartic acid (RGD) solution. The electrical conductivity of PDA/RGD SG/PCL and PDA/ RGD MG/PCL is 0.89 and $0.637 \mathrm{~S} \mathrm{~m}^{-1}$, respectively [11]. These reported conductivity values are much 
Table 4 Electrical resistance and conductivity of 3D graphene/polymer composites

\begin{tabular}{llllll}
\hline $\begin{array}{l}\text { 3D-GF/PCL } \\
\text { composite code }\end{array}$ & $\begin{array}{l}\text { Electrical resistance } \\
(\Omega)\end{array}$ & $\begin{array}{l}\text { Cross section area } \\
\left(\mathrm{mm}^{2}\right)\end{array}$ & $\begin{array}{l}\text { Tube length } \\
(\mathrm{mm})\end{array}$ & $\begin{array}{l}\text { Electrical resistivity } \rho \\
(\Omega \cdot \mathrm{m})\end{array}$ & $\begin{array}{l}\text { Electrical conductivity } \\
\left(\mathrm{S} \mathrm{m}^{-1}\right)\end{array}$ \\
\hline PCL scaffold & $\infty$ & - & - & - & - \\
Drop and dip-980 & 440 & 1.07 & 25 & 0.0188 & 53.2 \\
Drop and dip-1080 & 25 & 1.07 & 27 & 0.0010 & 1000 \\
PCL-CD-1080 & 30 & 14.13 & 25 & 0.0170 & 58.8 \\
PCL-CD-880 & 550 & 14.13 & 25 & 0.3109 & 3.2 \\
Mix-1080 & 17 & 14.13 & 26 & 0.0092 & 108.7 \\
\hline
\end{tabular}

lower than those of the current study, even for our worst $880{ }^{\circ} \mathrm{C}$ grown 3D-GF/PCL composite case. In conclusion, the 3D-GF provides an excellent conductive frame which it leads to higher electrical conductivity composites.

It is worth noting that the weight percent of graphene material (with respect to biodegradable filler such as PCL) in biomedical applications is extremely important. Tabish et al. synthesized graphene foams by CVD and implanted then in carp fishes at low $\left(5 \mathrm{mg} \mathrm{L}^{-1}\right)$, medium $\left(10 \mathrm{mg} \mathrm{L}^{-1}\right)$ and high $\left(15 \mathrm{mg} \mathrm{L}^{-1}\right)$ graphene doses. For the low dose, there was no sign of toxicity or any change in blood system [42]. In our work, the weight percent of 3D-GF in a composite tube with about $35 \mathrm{~mm}$ in length and $3 \mathrm{~mm}$ in inner diameter was between 0.4 and $4 \mathrm{mg}$, depending on the growth temperature. We conclude that the low carbon loading along with the high electrical conductivity makes the 3D-GF composites developed in this study extremely promising for biomedical applications.

It should be also mentioned that we could prepare the 3D-GF conductive composite by the sample which graphene has grown at $880{ }^{\circ} \mathrm{C}$ via Route- 2 only, while it was not possible by the drop and dip coating (Route-1). These "low temperature" graphene composites, which showed more than one order of magnitude lower conductivity, were easily broken during handling, and their mechanical properties could not be measured.

\section{Conclusions}

The current research work focuses on a method to fabricate three-dimensional graphene material foam, 3D-GF composites. Open-pore polymer composite tubes and slabs, on the scale of a few $\mathrm{cm}$, have been fabricated based on monolithic 3D-GF structures, and
CVD has grown on $\mathrm{Ni}$ foam templates. The 3D-GF was synthesized at different temperatures by induction heating chemical vapor deposition (or ICVD) and consists of a thin graphite layer covering homogeneously the Ni template, as evidenced by Raman and microscopy techniques. Cyclododecane was applied as a protective layer during the nickel removal to retain integrity, and shape of the monolithic 3D-GF (Routes-1-3) was developed for preparing these composites. The results show that the composites made by drop and dip coating (Route-1) were more flexible and exhibited better mechanical properties. Also, these monolithic 3D-GF/PCL composites are highly conductive, an excellent premise for nerve tissue engineering applications. Moreover, also a novel mesoporous polymer structure was produced by applying mixed of cyclododecane to PCL, whose properties can be changed by varying the solution composition. Furthermore, the graphene loading in the composites samples ranged between 1 and $7.3 \mathrm{wt} \%$ and we demonstrate that even the low graphene-loaded composites can be fabricated retaining good electrical properties.

\section{Acknowledgements}

The authors would like to thank International Centre for Theoretical Physics (ICTP) and Iran National Science Foundation (INSF) for their financial support of this research.

\section{Funding}

Open access funding provided by Ente per le Nuove Tecnologie, l'Energia e l'Ambiente within the CRUICARE Agreement. 
Supplementary Information: The online version of this article (https://doi.org/10.1007/s10853-020-055 96-1) contains supplementary material, which is available to authorized users.

Open Access This article is licensed under a Creative Commons Attribution 4.0 International License, which permits use, sharing, adaptation, distribution and reproduction in any medium or format, as long as you give appropriate credit to the original author(s) and the source, provide a link to the Creative Commons licence, and indicate if changes were made. The images or other third party material in this article are included in the article's Creative Commons licence, unless indicated otherwise in a credit line to the material. If material is not included in the article's Creative Commons licence and your intended use is not permitted by statutory regulation or exceeds the permitted use, you will need to obtain permission directly from the copyright holder. To view a copy of this licence, visit http://creativecommons.org/licen ses/by $/ 4.0 /$.

\section{References}

[1] Wang H, Li X, Baker-Fales M, Amama PB (2016) 3D graphene-based anode materials for Li-ion batteries. Curr Opin Chem Eng 13:124-132. https://doi.org/10.1016/j.coche.201 6.08 .009

[2] Bi H, Huang F, Liang J, Tang Y, Lü X, Xie X et al (2011) Large-scale preparation of highly conductive three dimensional graphene and its applications in CdTe solar cells. J Mat Chem 21:17366. https://doi.org/10.1039/c1jm13418c

[3] Yu F, Camilli L, Wang T, Mackenzie DMA, Curioni M, Akid $\mathrm{R}$ et al (2018) Complete long-term corrosion protection with chemical vapor deposited graphene. Carbon 132:78-84. h ttps://doi.org/10.1016/j.carbon.2018.02.035

[4] Yavari F, Koratkar N (2012) Graphene-based chemical sensors. Am Chem Soc 3:1746-1753. https://doi.org/10.1021/ jz300358t

[5] Zhao J, Ren W, Cheng H-M (2012) Graphene sponge for efficient and repeatable adsorption and desorption of water contaminations. J Mat Chem 22:20197. https://doi.org/10. 1039/C2JM34128J

[6] Qin Z, Jung GS, Kang MJ, Buehler JM (2017) The mechanics and design of a lightweight three-dimensional graphene assembly. Sci Adv 3(1):e1601536. https://doi.org/ 10.1126/sciadv.1601536
[7] Golafshan N, Kharaziha M, Fathi M (2017) Tough and conductive hybrid graphene-PVA: alginate fibrous scaffolds for engineering neural construct. Carbon 111:752-763. http s://doi.org/10.1016/j.carbon.2016.10.042

[8] Mohan VB, Lau K-t, Hui D, Bhattacharyya D (2018) Graphene-based materials and their composites: a review on production, applications and product limitations. Compos Part B-Eng 142:200-220. https://doi.org/10.1016/j.compo sitesb.2018.01.013

[9] Rouf TB, Kokini JL (2016) Biodegradable biopolymergraphene nanocomposites. J Mat Sci 51:9915-9945. https://d oi.org/10.1007/s10853-016-0238-4

[10] Jakus EA, Secor BE, Rutz LA, Jordan WS, Hersam CM, Shah NR (2015) Three dimensional printing of high-content graphene scaffolds for electronic and biomedical applications. Am Chem Soc. https://doi.org/10.1021/acsnano.5b 01179

[11] Qian Y, Zhao X, Han Q, Chen W, Li H, Yuan W (2018) An integrated multi-layer 3D-fabrication of PDA/RGD coated graphene loaded PCL nanoscaffold for peripheral nerve restoration. Nat Commu 9:323. https://doi.org/10.1038/s414 67-017-02598-7

[12] Kehoe S, Zhang XF, Boyd D (2012) FDA approved guidance conduits and wraps for peripheral nerve injury: a review of materials and efficacy. Injury 43:553-572. https://doi.org/ 10.1039/C3EE43385D

[13] Sayyar S, Murray E, Thompson BC, Gambhir S, Officer DL, Wallace GG (2013) Covalently linked biocompatible graphene/polycaprolactone composites for tissue engineering. Carbon 52:296-304. https://doi.org/10.3390/ma12182991

[14] Evlashin S, Dyakonov P, Tarkhov M, Dagesyan S, Rodionov S, Shpichka A et al (2019) Flexible polycaprolactone and polycaprolactone/graphene scaffolds for tissue engineering. Materials 12(18):2991. https://doi.org/10.3390/ma12182991

[15] Idowu A, Boesl B, Agarwal A (2018) 3D graphene foamreinforced polymer composites - a review. Carbon 135:52-71. https://doi.org/10.1016/j.carbon.2018.04.024

[16] Geetha Bai R, Muthoosamy K, Manickam S, Hilal-Alnaqbi A (2019) Graphene-based 3D scaffolds in tissue engineering: fabrication, applications, and future scope in liver tissue engineering. Int J Nanomedicine 14:5753-5783. https://doi. org/10.2147/IJN.S192779

[17] Chen Z, Ren W, Gao L, Liu B, Pei S, Cheng H-M (2011) Three-dimensional flexible and conductive interconnected graphene networks grown by chemical vapour deposition. Nat Mat 10:424-428. https://doi.org/10.1038/nmat3001

[18] Min Z, Wen-Long W, Xue-Dong B (2013) Preparing threedimensional graphene architectures: review of recent developments. Chinese Phys B 22(9):8105. https://doi.org/10.10 88/1674-1056/22/9/098105 
[19] Wang JK, Xiong GM, Zhu M, Ozyilmaz B, Castro Neto AH, Tan NS et al (2015) Polymer-enriched 3D graphene foams for biomedical applications. ACS Appl Mater Interfaces 7:8275-8283. https://doi.org/10.1021/acsami.5b01440

[20] Li N, Zhang Q, Gao S, Song Q, Huang R, Wang L et al (2013) Three-dimensional graphene foam as a biocompatible and conductive scaffold for neural stem cells. Sci rep 3:1-6. https://doi.org/10.1038/srep01604

[21] Trinsoutrot P, Vergnes H, Caussat B (2014) Three dimensional graphene synthesis on nickel foam by chemical vapor deposition from ethylene. Mater Sci Eng: B 179:12-16. h ttps://doi.org/10.1016/j.mseb.2013.09.018

[22] Lavin-Lopez MP, Valverde JL, Ruiz-Enrique MI, SanchezSilva L, Romero A (2015) Thickness control of graphene deposited over polycrystalline nickel. New J Chem 39:4414-4423. https://doi.org/10.1039/c5nj00073d

[23] Yavari F, Chen Z, Thomas AV, Ren W, Cheng HM, Koratkar N (2011) High sensitivity gas detection using a macroscopic three-dimensional graphene foam network. Sci Rep 1:166. h ttps://doi.org/10.1038/srep00166

[24] Bong J, Lim T, Seo K, Kwon CA, Park JH, Kwak SK et al (2015) Dynamic graphene filters for selective gas-water-oil separation. Sci Rep 5:14321. https://doi.org/10.1038/sre p00166

[25] Lim T, Lee J, Lee J, Ju S (2016) Detection of chemicals in water using a three-dimensional graphene porous structure as liquid-vapor separation filter. Nano Res 10:971-979. http s://doi.org/10.1007/s12274-016-1356-7

[26] Zhang Y, Gomez L, Ishikawa FN, Madaria A, Ryu K, Wang $\mathrm{C}$ et al (2010) Comparison of graphene growth on singlecrystalline and polycrystalline ni by chemical vapor deposition. J Phys Chem Lett 1:3101-3107. https://doi.org/10. 1016/j.tsf.2016.05.036

[27] Zhang Y, Zhang L, Zhou C (2011) Review of chemical vapor deposition of graphene and related applications. Am Chem Soc 46:2329-39. https://doi.org/10.1016/j.tsf.2016.05.036

[28] Presland AEB, Walker PL (1969) Growth of single-crystal graphite by pyrolysis of acetylene over metals. Carbon 7:1-4. https://doi.org/10.1016/0008-6223(69)90002-5

[29] Leclercq J, Sveshtarov P (2016) The Transfer of Graphene: A Review. Bulg. J. Phys 43: 121-47 https://www.bjp-bg.c om/papers/bjp2016_2_121-147.pdf

[30] Lin YC, Lu CC, Yeh CH, Jin C, Suenaga K, Chiu PW (2012) Graphene annealing: how clean can it be? Nano Lett 12:414-419. https://doi.org/10.1021/nl203733r

[31] Capasso A, De Francesco M, Leoni E, Dikonimos T, Buonocore F, Lancellotti L et al (2014) Cyclododecane as support material for clean and facile transfer of large-area few-layer graphene. App Phys Lett 105:113101. https://doi. org/10.1063/1.4895733

[32] Żelechowska K, Kondratowicz I, Sadowski W (2015) Carbon Nanotechnology. One Central Press (OCP), UK

[33] Nieto A, Boesl B, Agarwal A (2015) Multi-scale intrinsic deformation mechanisms of $3 \mathrm{D}$ graphene foam. Carbon 85:299-308. https://doi.org/10.1016/j.carbon.2015.01.003

[34] Hong S-W, Lee J, Kang SH, Hwang EY, Hwang Y-S, Lee H, Mi et al, (2014) Enhanced neural cell adhesion and neurite outgrowth on graphene-based biomimetic substrates. BioMed Res Inter, Article ID 212149 https://doi.org/https://d oi.org/10.1155/2014/212149

[35] Habibi A, Mousavi Khoie SM, FarzadMahboubi UM (2017) Fast synthesis of turbostratic carbon thin coating by cathodic plasma electrolysis. Thin Solid Films 621:253-258. https://d oi.org/10.1016/j.tsf.2016.05.036

[36] Pimenta MA, Dresselhaus G, Dresselhaus MS, Cancado LG, Jorio A, Saito R (2007) Studying disorder in graphite-based systems by Raman spectroscopy. Phys Chem Chem Phys 9:1276-12791. https://doi.org/10.1039/b613962k

[37] Ferrari AC (2007) Raman spectroscopy of graphene and graphite: disorder, electron-phonon coupling, doping and nonadiabatic effects. Solid State Commun 143:47-57. http s://doi.org/10.1016/j.ssc.2007.03.052

[38] Reina A, Jia X, Ho J, Nezich D, Son H, Bulovic V et al (2009) Large area, few-layer graphene films on arbitrary substrates by chemical vapor deposition. Nano Lett 9:30-35. https://doi.org/10.1021/n1801827v

[39] Malard LM, Pimenta MA, Dresselhaus G, Dresselhaus MS (2009) Raman spectroscopy in graphene. Phys Rep 473:51-87. https://doi.org/10.1016/j.physrep.2009.02.003

[40] Ferrari AC, Basko DM (2013) Raman spectroscopy as a versatile tool for studying the properties of graphene. Nat Nanotechnol 8:235-246. https://doi.org/10.1038/nnano.201 3.46

[41] Singleto M, Nash P (1989) The C-Ni (Carbon-Nickel) system. Bulletin of alloy phase diagrams 10:121-126. https://d oi.org/10.1007/BF02881419

[42] Tabish TA, Chabi S, Ali M, Xia Y, Jabeen F, Zhang S (2017) Tracing the bioavailability of three-dimensional graphene foam in biological tissues. Mater (Basel) 10(4):336. https://d oi.org/10.3390/ma10040336

Publisher's Note Springer Nature remains neutral with regard to jurisdictional claims in published maps and institutional affiliations. 